\title{
Toward understanding the underlying mechanisms of pelvic tilt reserve in adult spinal deformity: the role of the 3D hip orientation
}

\author{
Mario Mekhael ${ }^{1}$. Georges Kawkabani ${ }^{1} \cdot$ Renée Maria Saliby ${ }^{1} \cdot$ Wafa Skalli $^{2} \cdot$ Eddy Saad $^{1}$ - Elena Jaber ${ }^{1}$. \\ Rami Rachkidi ${ }^{1} \cdot$ Khalil Kharrat $^{1}$ - Gaby Kreichati ${ }^{1}$. Ismat Ghanem ${ }^{1}$. Virginie Lafage ${ }^{3}$. Ayman Assi ${ }^{1,2}$ (D)
}

\begin{abstract}
Purpose To explore 3D hip orientation in standing position in subjects with adult spinal deformity (ASD) presenting with different levels of compensatory mechanisms.

Methods Subjects with ASD $(n=159)$ and controls $(n=68)$ underwent full-body biplanar X-rays with the calculation of 3D spinopelvic, postural and hip parameters. ASD subjects were grouped as ASD with knee flexion (ASD-KF) if they compensated by flexing their knees (knee flexion $\geq 5^{\circ}$ ), and ASD with knee extension (ASD-KE) otherwise (knee flexion $<5^{\circ}$ ). Spinopelvic, postural and hip parameters were compared between the three groups. Univariate and multivariate analyses were then computed between spinopelvic and hip parameters.

Results ASD-KF had higher SVA ( $67 \pm 66 \mathrm{~mm}$ vs. $2 \pm 33 \mathrm{~mm}$ and $11 \pm 21 \mathrm{~mm}), \mathrm{PT}\left(27 \pm 14^{\circ}\right.$ vs. $18 \pm 9^{\circ}$ and $\left.11 \pm 7^{\circ}\right)$ and PI-LL mismatch $\left(20 \pm 26^{\circ}\right.$ vs $-1 \pm 18^{\circ}$ and $\left.-13 \pm 10^{\circ}\right)$ when compared to ASD-KE and controls (all $\left.p<0.05\right)$. ASD-KF also had a more tilted $\left(34 \pm 11^{\circ}\right.$ vs. $28 \pm 9^{\circ}$ and $\left.26 \pm 7^{\circ}\right)$, anteverted $\left(24 \pm 6^{\circ}\right.$ vs. $20 \pm 5^{\circ}$ and $\left.18 \pm 4^{\circ}\right)$ and abducted $\left(59 \pm 6^{\circ}\right.$ vs. $57 \pm 4^{\circ}$ and $\left.56 \pm 4^{\circ}\right)$ acetabulum, with a higher posterior coverage $\left(100 \pm 6^{\circ}\right.$ vs. $97 \pm 7^{\circ}$ for ASD-KE) when compared to ASD-KE and controls (all $p<0.05$ ). The main determinants of acetabular tilt, acetabular abduction and anterior acetabular coverage were PT, SVA and LL (adjusted $\mathrm{R}^{2}[0.12 ; 0.5]$ ).

Conclusions ASD subjects compensating with knee flexion have altered hip orientation, characterized by increased posterior coverage (acetabular anteversion, tilt and posterior coverage) and decreased anterior coverage which can together lead to posterior femoro-acetabular impingement, thus limiting pelvic retroversion. This underlying mechanism could be potentially involved in the hip-spine syndrome.
\end{abstract}

Keywords Adult spinal deformity $\cdot$ Hip $\cdot$ Spine $\cdot$ Acetabulum $\cdot$ Sagittal alignment $\cdot$ Knee flexion

\section{Introduction}

An aging of the worldwide population is actually being witnessed with the proportion of people over 60 predicted to increase [1], leading to an increase in bone and joint pathologies [2]. Aging of the human skeleton, along with muscle degeneration, can lead to many functional and psychological

Ayman Assi

ayman.assi@usj.edu.lb; ayman.assi@gmail.com

1 Laboratory of Biomechanics and Medical Imaging, Faculty of Medicine, University of Saint-Joseph, Beirut, Lebanon

2 Institut de Biomécanique Humaine Georges Charpak, Arts et Métiers ParisTech, Paris, France

3 Department of Orthopedic surgery, Hospital for Special Surgery, New York, USA burdens [3-5]. The scientific community has seen a rising interest in spinal pathologies that are quickly becoming a public health issue.

Adult spinal deformity (ASD) is defined by specific radiological measures [6]. ASD includes a wide spectrum of deformities, including adult scoliosis, progressive adolescent idiopathic scoliosis in adult patients, hyperkyphosis and sagittal deformity (iatrogenic, degenerative or posttraumatic) [7]. ASD patients are known to present sagittal malalignment leading to the recruitment of compensatory mechanisms in order to maintain a horizontal gaze, and to keep their head and center of gravity above their feet [8]. These compensatory mechanisms spread from the cervical spine proximally down to the lower limbs distally [9-11]. The succession of the events participating in this chain of mechanisms is well studied in the literature [11-16]. The 
deformity usually begins at the level of the spine and is characterized by a flattening of the spinal curvatures, especially at the lumbar level, even leading to an inversion in certain severe stages. This then leads to a pelvic retroversion as a compensatory mechanism [17], causing an extension at the level of the hips. Knee flexion develops in later stages in order to palliate for the exhaustion of said hip extension $[11,14,18]$ and is generally considered as the final stage of compensation [19].

It is known that with the exhaustion of pelvic tilt reserve, the only remaining mechanism to maintain the head over the feet is to flex the knees. Moreover, subjects with ASD were found to have an anteverted acetabulum when compared to controls [20], with a decrease in this anteversion reported after spinal correction. Also, previous studies have showed that increased acetabular anteversion was associated with both increased pelvic incidence [21] and pelvic tilt [22]. Therefore, it was hypothesized that hip morphology is involved in the chain of compensation and in the limitation of pelvic tilt reserve.

As such, the aim of this study was to explore the 3D hip morphology in the standing position in subjects with ASD presenting at different stages of compensation.

\section{Methods}

This is an IRB-approved cross-sectional monocentric study where subjects with ASD consulting our center for radiographic follow-up were enrolled. Subjects were included if they were $>20$ years and had back pain, with at least one of the radiographic diagnostic criteria as defined by the International Spine Study Group [6]: pelvic tilt (PT) $>25^{\circ}$, Cobb angle $>20^{\circ}$, sagittal vertical axis (SVA) $>50 \mathrm{~mm}$, or thoracic kyphosis (TK) $>60^{\circ}$. A control group was also enrolled and included subjects with no back pain or orthopedic history.

Demographic parameters (age, weight, height and sex) were collected. Full-body biplanar standing radiographs were performed (EOS Imaging ${ }^{\circledR}$, Paris, France) for all subjects in the freestanding position [23]. Then, 3D reconstructions of the spine and lower limbs were performed by well-trained operators using the SterEOS ${ }^{\circledR}$ software (EOS Imaging ${ }^{\circledR}$, Paris, France; version 2019), and the pelvis was reconstructed in 3D using a specific software (Arts et Métiers ParisTech, Paris, France). Briefly, the 3D reconstruction technique of the pelvis is based on the detection of anatomical landmarks of the pelvis and proximal femur, on both the lateral and frontal radiographs, such as sacral plate contour, sacroiliac joint, acetabular rims, anterior-superior iliac spine, pubic symphysis, greater trochanter, femoral neck and femoral condyles. This allows a first estimation of the 3D pelvis shape that can be retroprojected on both images. The model is then adjusted by modifying the pelvic contours on both frontal and lateral radiographs for a best fit between retroprojected and radiographic contours [24].

Spinopelvic and global postural parameters were generated from the 3D skeletal reconstructions: SVA (in mm), CAM plumb line (in $\mathrm{mm}$, as the sagittal distance between the center of auditory meatus plumb line and the posterior corner of the sacrum), C7-CSL (in mm, as the frontal deviation of the C7 plumb line to the middle of the sacral plate), lumbar lordosis L1S1 (LL, in ${ }^{\circ}$ ), thoracic kyphosis T1T12 (TK, in ${ }^{\circ}$ ), Cobb angle (in ${ }^{\circ}$ ), pelvic incidence (PI, in), PI-LL mismatch (in ${ }^{\circ}$ ), pelvic tilt $\left(\mathrm{PT}\right.$, in $\left.^{\circ}\right)$ and knee flexion $\left(\mathrm{KF}\right.$, in $^{\circ}$ : flexion+/extension -) (Fig. 1).

The following hip parameters were calculated from the 3D pelvic reconstructions: acetabular anteversion (AAnt, in ${ }^{\circ}$ ), abduction (AAbd, in ${ }^{\circ}$ ), tilt (AT, in ${ }^{\circ}$ ), anterior and posterior coverage angles (AACA and PACA, respectively, in ${ }^{\circ}$ ). As for the lower limbs, acetabular coverage over the femoral head (ACFH, in \%), neck shaft angle (NSA, in ${ }^{\circ}$ ) and femoral anteversion $\left(\mathrm{FA}\right.$, in $^{\circ}$ ) were calculated (Fig. 2).

\section{Statistics}

At first, demographic parameters were compared between ASD subjects and controls using the Mann-Whitney test for age, weight and height and a chi-squared test for sex. The spinopelvic and global postural parameters were also compared between ASD subjects and controls using the Mann-Whitney test.

Then, in order to investigate the differences in hip morphology between different strategies of compensation in ASD, patients who presented with knee flexion $\geq 5^{\circ}$ were grouped as ASD with knee flexion (ASD-KF), and those with knee flexion $<5^{\circ}$ were grouped as ASD with knee extension (ASD-KE).

In order to assess the discrepancies in spinopelvic and postural alignment as well as hip parameters between ASD-KF, ASD-KE and controls, a Kruskal-Wallis test was applied followed by Conover-Iman pairwise comparisons with a Bonferroni correction.

The relationship between hip parameters and spinopelvic parameters was investigated through a univariate analysis, using Pearson's correlations. Then, in order to investigate the determinants of hip parameters among spinopelvic and postural alignment parameters, stepwise multiple linear regressions were computed while controlling for demographic variables. Xlstat ${ }^{\circledR}$ (Addinsoft ${ }^{\circledR}$, Paris, France; version 2020.1.3.65336) was used for the statistical analysis. The level of significance was set at 0.05 . 

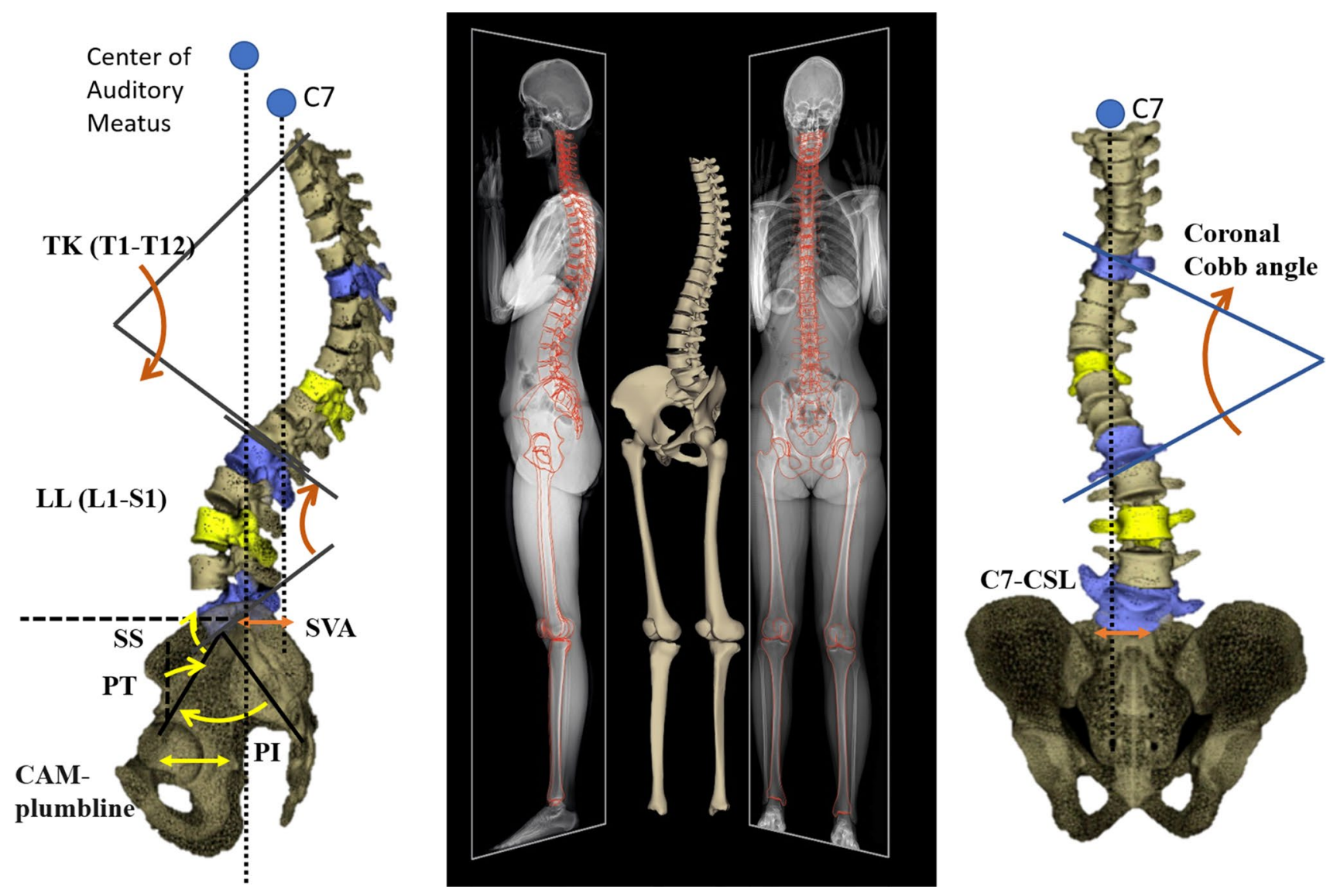

Fig. 1 Subject-specific 3D reconstructions of the spine and pelvis based on biplanar X-rays with computation of spinopelvic and global postural parameters

\section{Results}

In total, 159 ASD (126F and $33 \mathrm{M})$ and 68 controls $(51 \mathrm{~F}$ and $17 \mathrm{M})$ were included. There were no significant differences between the two groups for age (ASD $=46 \pm 21$ vs. controls $=39 \pm 13$ years, $p=0.052$ ), weight $(\mathrm{ASD}=69 \pm 17$ vs. controls $=68 \pm 14 \mathrm{~kg}, p=0.883)$ and sex $(p=0.352)$. Subjects with ASD were shorter than controls $(\mathrm{ASD}=162 \pm 10$ vs. controls $=165 \pm 8 \mathrm{~cm}, p=0.015$; Table 1 ).

When comparing spinopelvic and global postural parameters between ASD subjects and controls, ASD subjects were found to have an increased SVA as expected $(29 \pm 59$ vs. $-11 \pm 21 \mathrm{~mm}, p<0.001)$, CAM plumb line $(1.3 \pm 57$ vs. $-27 \pm 25 \mathrm{~mm}, p=0.001)$, knee flexion ( $6 \pm 10$ vs. $-1 \pm 5^{\circ}$, $p<0.001)$, $\mathrm{PT}\left(22 \pm 12\right.$ vs. $\left.11 \pm 7^{\circ}, p<0.001\right)$, Cobb angle $\left(26 \pm 17\right.$ vs. $\left.4 \pm 6^{\circ}, p<0.001\right)$ and a decreased LL $(51 \pm 22$ vs $\left.62 \pm 10^{\circ}, p<0.001\right)$.

When assessing patients according to knee flexion compensation, 67 ASD presented with knee flexion $\left(\geq 5^{\circ}\right)$ and were included in the ASD-KF group, while 92 had knee extension $\left(<5^{\circ}\right)$ and were included in the ASD-KE group. Patients in the ASD-KF group had a more pronounced sagittal malalignment compared to the ASD-KE and control groups, characterized by a higher SVA $(67 \pm 66 \mathrm{~mm}$ vs. $2 \pm 33 \mathrm{~mm}$ and $-11 \pm 21 \mathrm{~mm}$ resp., $p<0.001)$, knee flexion as expected $\left(15 \pm 9^{\circ}\left[5^{\circ} ; 50^{\circ}\right]\right.$ vs. $-1 \pm 4^{\circ}\left[-13^{\circ} ; 5^{\circ}\right]$ and $-1 \pm 5^{\circ}\left[-12^{\circ} ; 11^{\circ}\right]$ resp., $\left.p<0.001\right)$, PT $\left(27 \pm 14^{\circ}\right.$ vs. $18 \pm 9^{\circ}$ and $11 \pm 7^{\circ}$ resp., $\left.p<0.001\right)$ and PI-LL mismatch $\left(20 \pm 26^{\circ}\right.$ vs $-1 \pm 18^{\circ}$ and $-13 \pm 10^{\circ}$ resp., $p<0.001$ ). Patients in the ASD-KE group had an increased Cobb angle compared to the ASD-KF and control groups $\left(29 \pm 17^{\circ}\right.$ vs. $23 \pm 16^{\circ}$ and $4 \pm 6^{\circ}$ resp., $p<0.001$ ) (Fig. 3).

When investigating hip parameters, patients in the ASD$\mathrm{KF}$ group were found to have increased acetabular coverage of the femoral head compared to the ASD-KE and control groups $(48 \pm 4 \%$ vs. $46 \pm 4 \%$ and $44 \pm 4 \%$ resp., $p<0.001)$, AT $\left(34 \pm 11^{\circ}\right.$ vs. $28 \pm 9^{\circ}$ and $26 \pm 7^{\circ}$ resp., $\left.p<0.001\right)$, AAbd $\left(59 \pm 6^{\circ}\right.$ vs, $57 \pm 4^{\circ}$ and $56 \pm 4^{\circ}$ resp., $p=0.009$ and AAnt $\left(24 \pm 6^{\circ}\right.$ vs. $20 \pm 5^{\circ}$ and $18 \pm 4^{\circ}$ resp., $\left.p<0.001\right)$. However, for the case of the PACA, differences were found only between the ASD-KF and ASD-KE groups $\left(100 \pm 6^{\circ}\right.$ vs. $97 \pm 7^{\circ}$ resp., $p=0.006$ ). Moreover, patients in the ASD$\mathrm{KF}$ group had decreased AACA compared to the ASD-KE and control groups $\left(54 \pm 8^{\circ}\right.$ vs. $55 \pm 8^{\circ}$ and $60 \pm 6^{\circ}$ resp., 


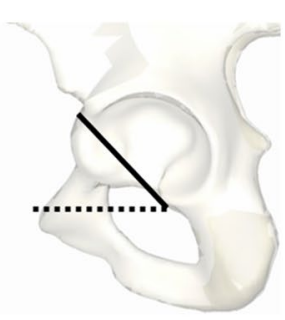

$$
\begin{gathered}
\text { Acetabular } \\
\text { tilt }\left({ }^{\circ}\right)
\end{gathered}
$$

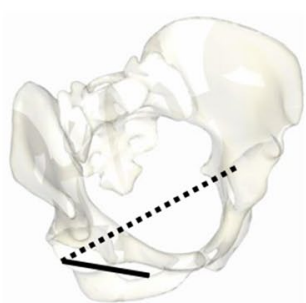

Anterior acetabular coverage $\left({ }^{\circ}\right)$

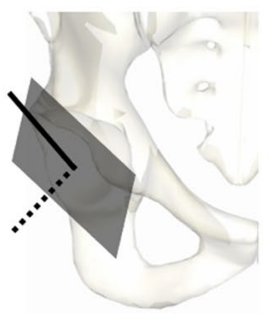

Acetabular abduction $\left({ }^{\circ}\right)$

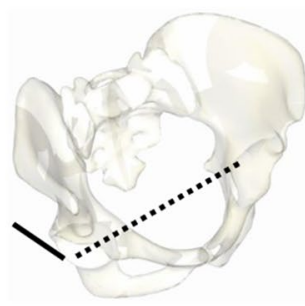

Posterior acetabular coverage $\left({ }^{\circ}\right)$

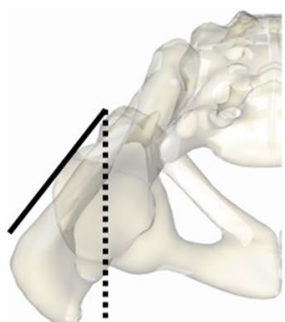

Acetabular anteversion $\left({ }^{\circ}\right)$

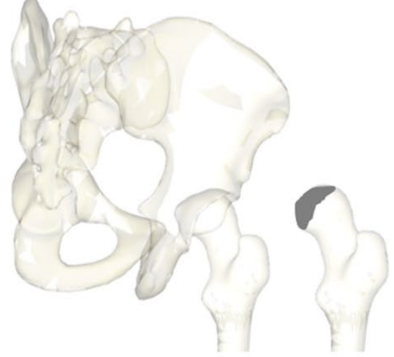

Acetabular coverage of the femoral head (\%)

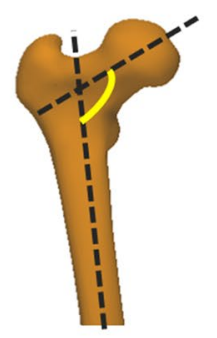

Neck Shaft Angle ( $\left.{ }^{\circ}\right)$

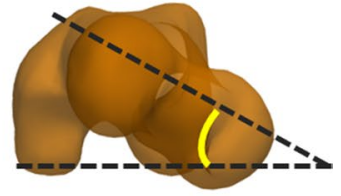

Femoral

Anteversion $\left({ }^{\circ}\right)$

Fig. 2 3D Hip parameters

Table 1 Demographic parameters and comparison between ASD subjects and controls

\begin{tabular}{llll}
\hline & ASD subjects $(n=159)$ & Controls $(n=68)$ & $p$ value \\
\hline Age (years) & $47 \pm 21$ & $38.6 \pm 12.9$ & 0.052 \\
Weight (Kg) & $68 \pm 17$ & $67 \pm 14$ & $165 \pm 7$ \\
Height (cm) & $162 \pm 10$ & & \\
Sex & & 31 & \\
F & 128 & 17 & 0.883 \\
M & 51 & $\mathbf{0 . 0 1 5 *}$ \\
\hline
\end{tabular}

*bold: significant difference

$p<0.001$ ) (Fig. 4). In addition, ASD-KF had a decreased NSA compared to the ASD-KE and control groups $(126 \pm 6$ vs. $128 \pm 6$ and $129 \pm 5^{\circ}$ resp., $\left.p=0.012\right)$, and FA $\left(12 \pm 9^{\circ}\right.$ vs. $16 \pm 11^{\circ}$ and $15 \pm 8^{\circ}$ resp., $p=0.03$ ).

Hip parameters were found to be significantly correlated with spinopelvic and postural parameters (Table 2). For instance, positive correlations were found between PT and AT $(r=0.68, p=0.012)$, and AAnt $(r=0.68, p=0.001)$. AT was also found to be positively correlated with SVA $(r=0.47, p<0.001)$. Furthermore, AAnt was positively correlated with PI-LL mismatch $(r=0.59, p<0.001)$.

The multivariate analysis showed that the increase in ACFH was determined (adjusted $\mathrm{R}^{2}=0.12$ ) by increasing age $(\beta=0.18)$ and $\mathrm{PT}(\beta=0.23)$. The increased
AT was determined (adjusted $\mathrm{R}^{2}=0.5$ ) by decreasing height $(\beta=-0.16)$ and increasing SVA $(\beta=0.14)$ and PT $(\beta=0.56)$. The increased AAbd was determined (adjusted $\left.\mathrm{R}^{2}=0.33\right)$ by decreasing weight $(\beta=-0.15)$ and increasing PT $(\beta=0.49)$ and SVA $(\beta=0.16)$. Furthermore, increased posterior coverage of the acetabulum was found to be determined (adjusted $\mathrm{R}^{2}=0.22$ ) by increasing age $(\beta=0.15)$ and PT $(\beta=0.29)$ and decreasing height $(\beta=-0.17)$ and Cobb angle $(\beta=-0.14)$. Moreover, an increase in the anterior coverage of the acetabulum was found to be determined (adjusted $\mathrm{R}^{2}=0.24$ ) by decreasing PT $(\beta=-0.34)$ and Cobb angle $(\beta=-0.18)$ and increasing L1S1 $(\beta=0.16)$. Increased AAnt (adjusted $\left.\mathrm{R}^{2}=0.49\right)$ was found to be determined by increasing age $(\beta=0.15)$ 

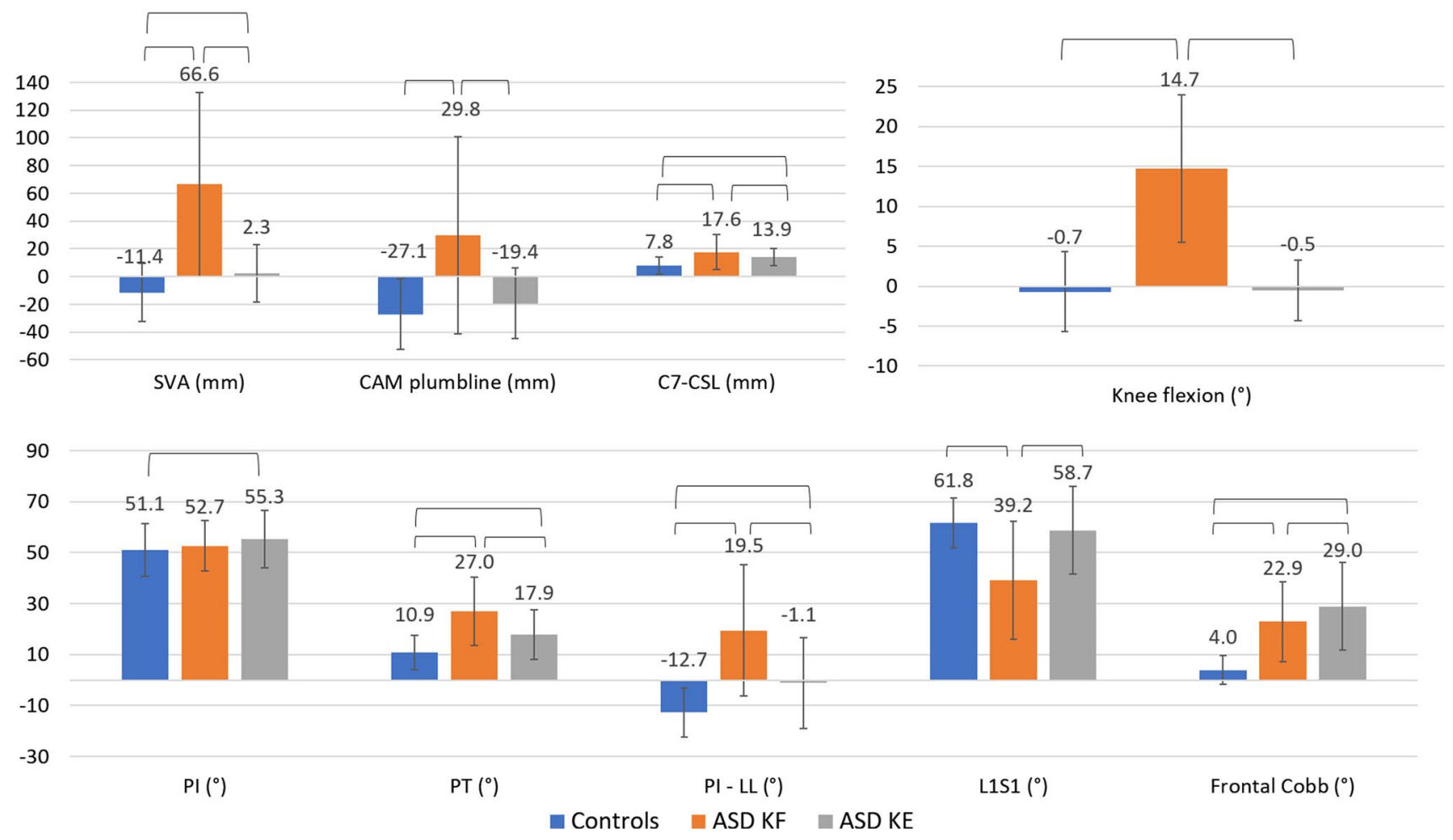

Fig. 3 Spinopelvic and global postural parameters: comparison between controls, ASD subjects presenting with knee flexion and ASD subjects presenting with knee extension

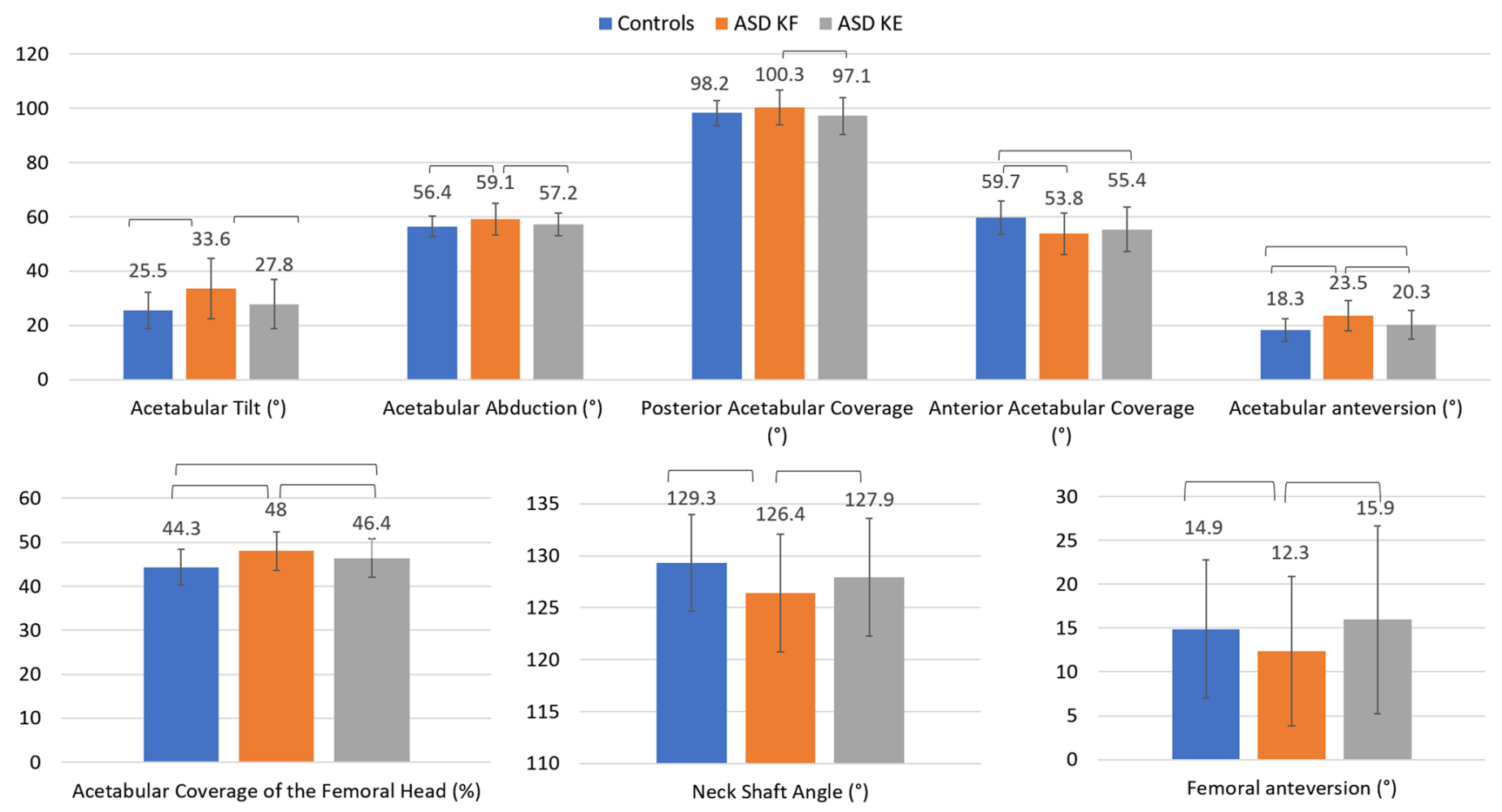

Fig. 4 3D hip parameters: comparison between controls, ASD presenting with knee flexion and ASD presenting with knee extension 
Table 2 Pearson's correlations between hip parameters and spinopelvic and postural alignment

\begin{tabular}{|c|c|c|c|c|c|c|c|c|c|c|}
\hline Pearson's correlation $(r)$ & SVA & CAM plumb line & C7-CSL & Knee flexion & PI & PT & PI-LL & L1S1 & T1T12 & Frontal Cobb \\
\hline Acetabular tilt & 0.47 & 0.25 & 0.21 & 0.30 & 0.17 & 0.68 & 0.57 & -0.40 & -0.15 & \\
\hline Acetabular abduction & 0.39 & 0.19 & & 0.20 & & 0.55 & 0.42 & -0.31 & -0.17 & \\
\hline Acetabular anteversion & 0.45 & 0.22 & 0.27 & 0.30 & 0.23 & 0.68 & 0.59 & -0.42 & -0.14 & \\
\hline Posterior acetabular coverage & 0.23 & & & & 0.21 & 0.41 & 0.30 & -0.20 & & \\
\hline Anterior acetabular coverage & -0.31 & -0.17 & -0.23 & -0.25 & & -0.44 & -0.41 & 0.36 & & -0.23 \\
\hline $\begin{array}{l}\text { Acetabular coverage over the } \\
\text { femoral head }\end{array}$ & 0.17 & & 0.15 & 0.23 & & 0.32 & 0.25 & -0.16 & & \\
\hline Neck shaft angle & -0.30 & -0.21 & & -0.24 & & -0.28 & -0.32 & 0.28 & & \\
\hline Femoral anteversion & -0.15 & & & -0.17 & -0.15 & -0.23 & & & & \\
\hline
\end{tabular}

Only significant correlations were reported

and PT $(\beta=0.6)$ and decreasing height $(\beta=-0.13)$. Major determinants are shown in Fig. 5.

\section{Discussion}

Subjects with adult spinal deformity are known to present with sagittal malalignment leading to the recruitment of several compensatory mechanisms in order to maintain balance, such as flattening of the thoracic spine, pelvic retroversion to a certain limit, and knee flexion [9-14, 25]. This study investigated hip morphology in subjects with ASD presenting with different compensatory strategies in order to better understand the concept of pelvic tilt reserve. It was shown in this study that subjects with ASD with flexed knees presented with a more posteriorly tilted acetabulum, leading to an increase in posterior coverage and a decrease in anterior coverage, along with an increase in abduction and
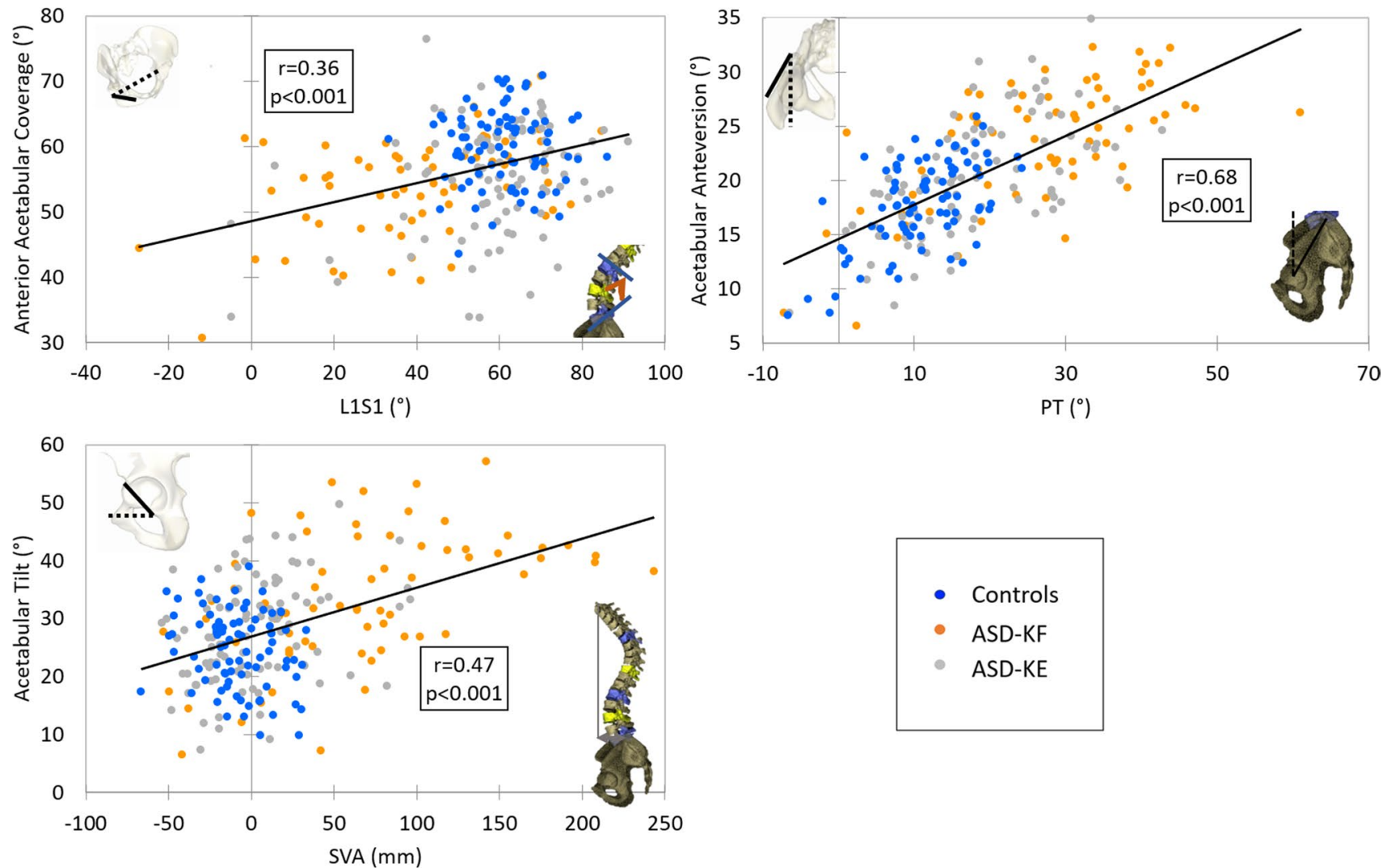

Fig. 5 Major correlations between hip parameters and spinopelvic and global postural parameters 
anteversion. These alterations in the acetabulum were determined by the increased SVA and PT and the decreased LL.

ASD patients included in this study present the typical postural malalignment previously described in the literature: increased SVA, PT, knee flexion, frontal Cobb angle and decreased lumbar lordosis. It is known that subjects with ASD retrovert their pelvises in an attempt to shift the center of gravity posteriorly [26-29]. However, this pelvis retroversion can reach a limit beyond which no further retroversion is possible. Therefore, in order to increase retroversion, ASD subjects tend to flex their knees as a final compensatory mechanism [16].

By comparing ASD subjects with knee flexion to those without knee flexion and controls, ASD who flexed their knees were found to present with greater alterations of radiological parameters and an increased sagittal malalignment. In fact, ASD subjects with knee flexion had an increased SVA and CAM plumb line and thus increased forward bending of the trunk and head. This finding further emphasizes that subjects with flexed knees have a more advanced sagittal malalignment. In addition, ASD subjects with knee flexion had a lower LL and therefore a greater PI-LL mismatch. Actually, previous studies have shown that an exhaustion of pelvic retroversion occurred with increased PI-LL mismatch [30] correlating with a more advanced stage of sagittal malalignment.

When assessing the hip parameters, ASD subjects with knee flexion presented with altered acetabular parameters when compared to ASD with knee extension and controls. In fact, an increasing pelvic retroversion, as seen in the group of ASD with increased knee flexion, would lead geometrically to an increased acetabular tilt posteriorly. Given the $3 \mathrm{D}$ orientation of the acetabulum, when the posterior coverage of the femoral head increases, this leads to decreased anterior coverage. In addition, the acetabulum will be more abducted and anteverted. This mechanism was validated by the results obtained in this study (Fig. 6). Previous studies have shown that ASD subjects tend to have altered acetabulum orientation characterized by increased acetabular anteversion [20]. Moreover, the findings of this study showed that ASD subjects who tend to compensate with additional knee flexion had a lowered neck shaft angle and femoral anteversion.

These alterations all together could play a role in limiting the retroversion of the pelvic segment as well as in the development of a femoro-acetabular impingement leading to the deterioration of the hip joint and therefore a decrease in function.

Future studies should include a larger sample in order to determine whether the reduced neck shaft angle and femoral anteversion are due to measurement errors or to bone remodeling in patients with spinal malalignment compensating with knee flexion.

Previous studies have shown better outcomes for patients without sagittal malalignment undergoing total hip arthroplasty than patients with sagittal malalignment [31]. Also, it is known that patients with spinal fusion, therefore reduced spinal mobility, are at highest risk of hip impingement [32]. The relationship between the spine and the hip is previously described in the literature as the spine-hip syndrome. However, the exact interaction between these two structures remains not fully elucidated $[33,34]$. In this study, increased PI-LL mismatch and knee flexion were found to be correlated with increased acetabular tilt. In addition, increased SVA, knee flexion and PI-LL mismatch were positively correlated with the increased acetabular anteversion. These correlations further accentuate the findings seen in ASD patients who compensate
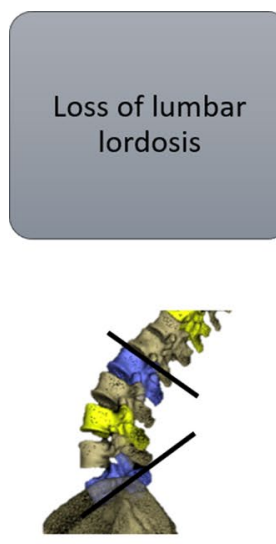
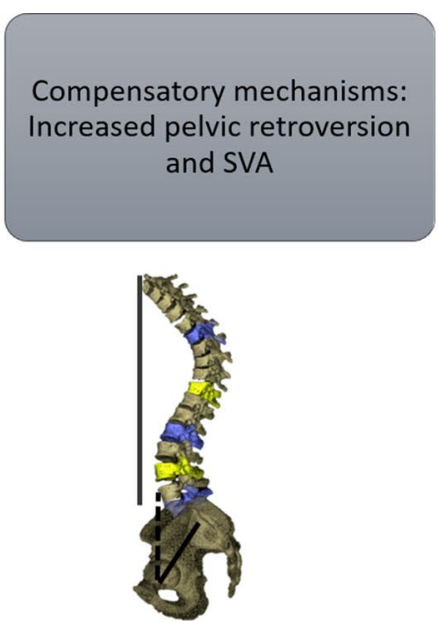
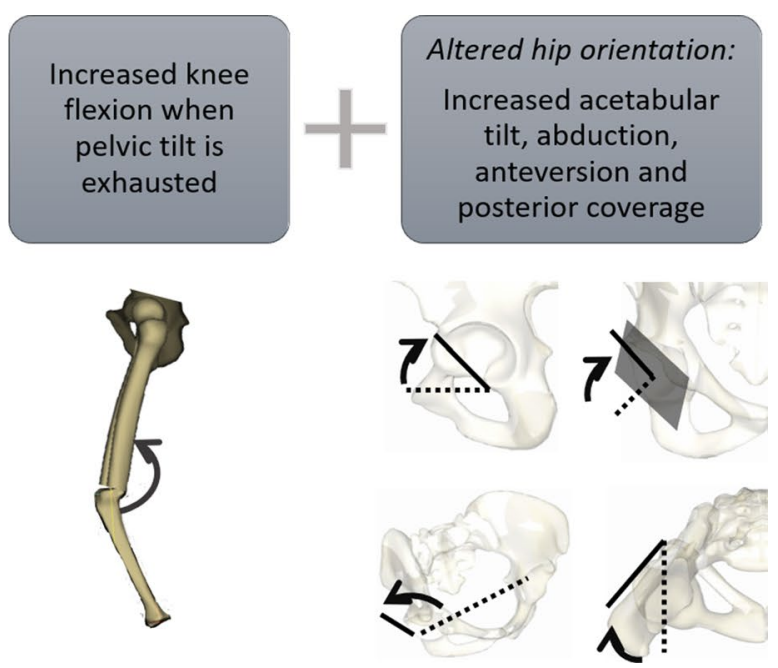

Fig. 6 Chain of compensation in patients with ASD and influence on 3D hip orientation 


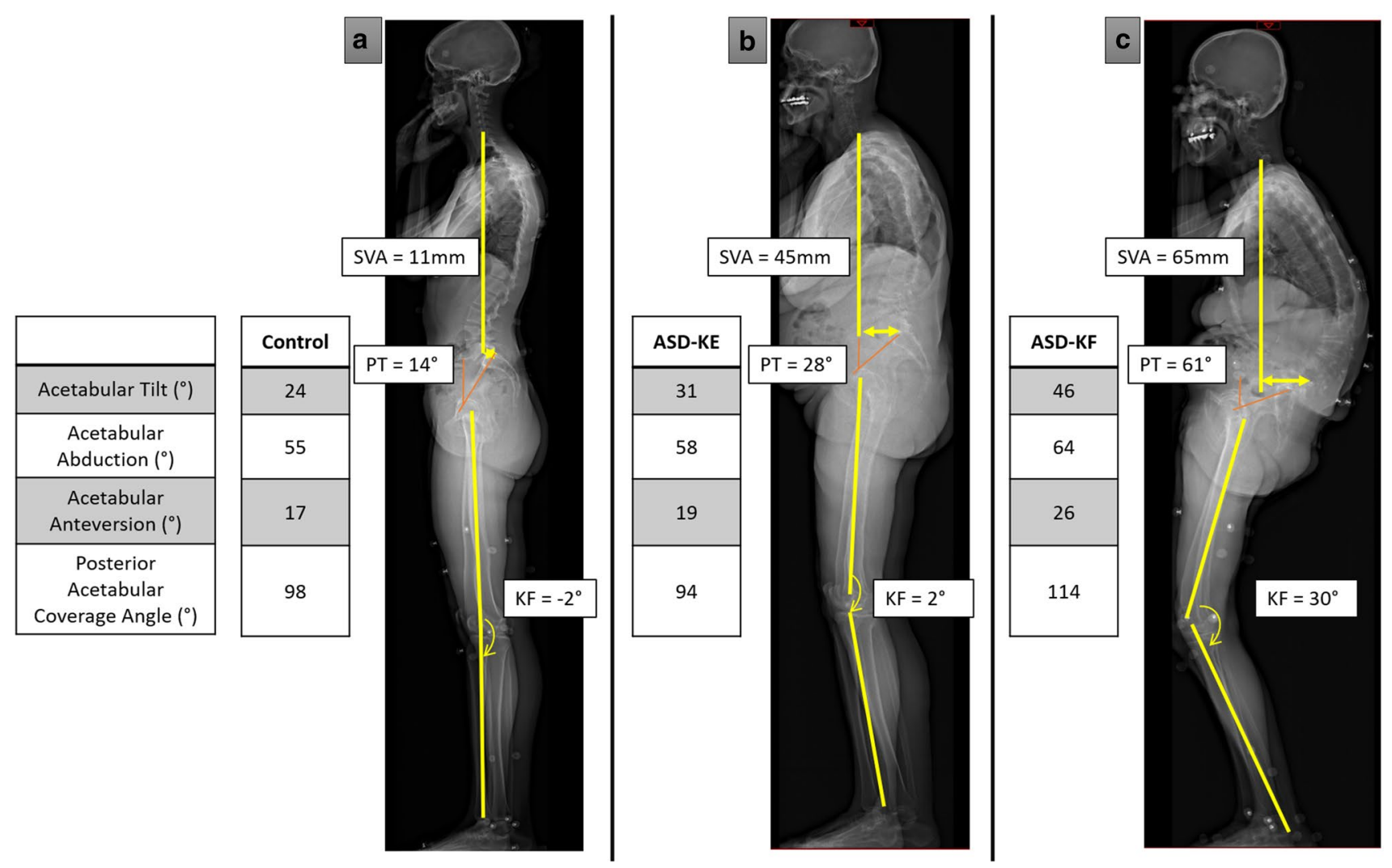

Fig. 7 Examples of spinopelvic, global postural and hip parameters in control subject (a), patient with ASD presenting with knee extension (b) and patient with ASD presenting with knee flexion (c)

with knee flexion. Thus, a more severe sagittal malalignment might be associated with changes in acetabular orientation (Fig. 7). Furthermore, even the morphological alterations of the hip, such as the decreased neck shaft angle and femoral anteversion, were also correlated with the sagittal malalignment parameters.

In the multivariate analysis, PT was found to be a determinant of all acetabular parameters, showing the importance of this parameter in the chain of compensation and as a main determinant for the resulting hip orientation. Furthermore, other spinopelvic parameters like SVA and LL were found to be determinants of acetabular tilt, abduction and anterior coverage, thus emphasizing the close relationship between sagittal malalignment and hip orientation. Future studies should confirm if the correction of spinopelvic deformities can lead to subsequent adjustments in acetabular orientation.

In conclusion, this study showed that ASD subjects compensating with knee flexion had an increased pelvic tilt and presented a more tilted acetabulum, with decreased anterior coverage and increased posterior coverage, anteversion and abduction. These alterations might lead to femoro-acetabular impingement, thus limiting the increase in pelvic tilt, and thereby resulting in knee flexion in order to further compensate for increasing sagittal malalignment. This underlying mechanism could be potentially involved in the hip-spine syndrome.

Acknowledgements This research was funded by the University of Saint-Joseph (grant FM361) and EUROSPINE (TFR2020\#22). The funding sources did not intervene in study design; in the collection, analysis and interpretation of data; in the writing of the report; and in the decision to submit the article for publication.

Conflict of interest MM, GK, RMS, ES, WS, EJ, RR, KK, GK, IG, $\mathrm{VL}$ and AA, declare that they have no conflict of interest related to this study.

\section{References}

1. Lutz W, Sanderson W, Scherbov S (2008) The coming acceleration of global population ageing. Nature 451:716-719. https://doi. org/10.1038/nature06516

2. Schwab F, Dubey A, Gamez L et al (2005) Adult scoliosis: prevalence, SF-36, and nutritional parameters in an elderly volunteer population. Spine (Phila Pa 1976) 30:1082-1085. https://doi. org/10.1097/01.brs.0000160842.43482.cd

3. Bess S, Line B, Fu K-M et al (2016) The health impact of symptomatic adult spinal deformity: comparison of deformity types to United States population norms and chronic diseases. Spine (Phila Pa 1976) 41:224-33. https://doi.org/10.1097/BRS.00000 00000001202 
4. Ferrero E, Skalli W, Lafage V et al (2019) Relationships between radiographic parameters and spinopelvic muscles in adult spinal deformity patients. Eur Spine J. https://doi.org/10.1007/s0058 6-019-06243-3

5. Schwab F, Dubey A, Pagala M et al (2003) Adult scoliosis: a health assessment analysis by SF-36. Spine Phila (Pa 1976) 28:602-606. https://doi.org/10.1097/01.BRS.0000049924.94414 .BB

6. Kim HJ, Iyer S, Diebo BG et al (2018) Clinically significant thromboembolic disease in adult spinal deformity surgery: incidence and risk factors in 737 patients. Glob spine J 8:224-230. https://doi.org/10.1177/2192568217724781

7. Diebo BG, Shah NV, Boachie-Adjei O et al (2019) Adult spinal deformity. Lancet 394:160-172. https://doi.org/10.1016/S0140 -6736(19)31125-0

8. Dubousset J (1994) Three-dimensional analysis of the scoliotic deformity. Pediatr Spine 1994:479-496

9. Barrey C, Roussouly P, Le Huec J-C et al (2013) Compensatory mechanisms contributing to keep the sagittal balance of the spine. Eur Spine J 22:834-841. https://doi.org/10.1007/s0058 6-013-3030-z

10. Barrey C, Roussouly P, Perrin G, Le Huec J-C (2011) Sagittal balance disorders in severe degenerative spine. Can we identify the compensatory mechanisms? Eur Spine J 20:626-633. https:// doi.org/10.1007/s00586-011-1930-3

11. Lafage V, Schwab F, Skalli W et al (2008) Standing balance and sagittal plane spinal deformity: analysis of spinopelvic and gravity line parameters. Spine (Phila Pa 1976) 33:1572-1578. https://doi. org/10.1097/BRS.0b013e31817886a2

12. Lazennec J-Y, Brusson A, Rousseau M-A (2013) Lumbarpelvic-femoral balance on sitting and standing lateral radiographs. Orthop Traumatol Surg Res 99:S87-S103. https://doi. org/10.1016/j.otsr.2012.12.003

13. Legaye J, Duval-Beaupère G, Hecquet J, Marty C (1998) Pelvic incidence: a fundamental pelvic parameter for three-dimensional regulation of spinal sagittal curves. Eur Spine J 7:99-103. https ://doi.org/10.1007/s005860050038

14. Obeid I, Hauger O, Aunoble S et al (2011) Global analysis of sagittal spinal alignment in major deformities: correlation between lack of lumbar lordosis and flexion of the knee. Eur Spine J 20:681-685. https://doi.org/10.1007/s00586-011-1936-x

15. Vialle R, Levassor N, Rillardon L et al (2005) Radiographic analysis of the sagittal alignment and balance of the spine in asymptomatic subjects. J Bone Joint Surg Am 87:260-267. https://doi. org/10.2106/JBJS.D.02043

16. Lafage R, Liabaud B, Diebo BG et al (2017) Defining the role of the lower limbs in compensating for sagittal malalignment. Spine Phila Pa 1976. https://doi.org/10.1097/BRS.0000000000002157

17. Lafage V, Schwab F, Patel A et al (2009) Pelvic tilt and truncal inclination: two key radiographic parameters in the setting of adults with spinal deformity. Spine (Phila Pa 1976) 34:E599_ E606. https://doi.org/10.1097/BRS.0b013e3181aad219

18. Hovorka I, Rousseau P, Bronsard N et al (2008) Mesure de la réserve d'extension de la hanche en relation avec le rachis. Étude comparative de deux méthodes radiologiques. Rev Chir Orthop Reparatrice Appar Mot 94:771-776. https://doi.org/10.1016/j. rco.2008.03.033

19. Obeid I, Hauger O, Aunoble S et al (2011) Global analysis of sagittal spinal alignment in major deformities: correlation between lack of lumbar lordosis and flexion of the knee. Eur Spine J 20(Suppl 5):681-685. https://doi.org/10.1007/s00586-011-1936-x

20. Buckland AJ, Vigdorchik J, Schwab FJ et al (2015) Acetabular anteversion changes due to spinal deformity correction: bridging the gap between hip and spine surgeons. J Bone Joint Surg Am 97:1913-1920. https://doi.org/10.2106/JBJS.O.00276
21. Thelen T, Thelen P, Demezon H et al (2017) Normative 3D acetabular orientation measurements by the low-dose EOS imaging system in 102 asymptomatic subjects in standing position: analyses by side, gender, pelvic incidence and reproducibility. Orthop Traumatol Surg Res 103:209-215. https://doi.org/10.1016/j. otsr.2016.11.010

22. Assi A, Mekhael M, Nacouzi R et al (2019) P 126 - Towards understanding the hip-spine syndrome in adults: a $3 \mathrm{~d}$ approach in standing position. Gait Posture. https://doi.org/10.1016/j.gaitp ost.2019.07.293

23. Faro FD, Marks MC, Pawelek J, Newton PO (2004) Evaluation of a functional position for lateral radiograph acquisition in adolescent idiopathic scoliosis. Spine (Phila Pa 1976) 29:2284-2289

24. Ghostine B, Sauret C, Assi A et al (2017) Influence of patient axial malpositioning on the trueness and precision of pelvic parameters obtained from 3D reconstructions based on biplanar radiographs. Eur Radiol 27:1295-1302. https://doi.org/10.1007/s0033 $0-016-4452-x$

25. Vialle R (2005) Radiographic analysis of the sagittal alignment and balance of the spine in asymptomatic subjects. J Bone Jt Surg 87:260. https://doi.org/10.2106/JBJS.D.02043

26. Duval-Beaupère $G$, Schmidt $C$, Cosson $P$ (1992) A barycentremetric study of the sagittal shape of spine and pelvis: the conditions required for an economic standing position. Ann Biomed Eng 20:451-462. https://doi.org/10.1007/BF02368136

27. Minoda Y, Kobayashi A, Iwaki H et al (2008) Sagittal alignment of the lower extremity while standing in Japanese male. Arch Orthop Trauma Surg 128:435-442. https://doi.org/10.1007/s0040 2-007-0528-z

28. Schwab F, Skalli W, El Fegoun AB et al (2005) Center of gravity and radiographic posture analysis: a preliminary review of adult volunteers and adult patients affected by scoliosis. Spine (Phila Pa 1976) 30:1535-1540. https://doi.org/10.1097/01.brs.0000167534 $.49069 . e 9$

29. Tardieu C, Bonneau N, Hecquet JÔ et al (2013) How is sagittal balance acquired during bipedal gait acquisition? Comparison of neonatal and adult pelves in three dimensions. Evolutionary implications. J Hum Evol 65:209-222. https://doi.org/10.1016/j. jhevol.2013.06.002

30. Liu S, Lafage V, Ferrero E et al (2014) Chain of compensation related to PI-LL mismatch: a complete standing axis investigation including the lower extremities. Spine J 14:S74. https://doi. org/10.1016/j.spinee.2014.08.191

31. Prather H, Van Dillen LR, Kymes SM et al (2012) Impact of coexistent lumbar spine disorders on clinical outcomes and physician charges associated with total hip arthroplasty. Spine J 12:363-369. https://doi.org/10.1016/j.spinee.2011.11.002

32. Stefl M, Lundergan W, Heckmann N et al (2017) Hip arthroplasty: avoiding and managing problems spinopelvic mobility and acetabular component position for total hip arthroplasty. Bone Jt J 99B:37-45. https://doi.org/10.1302/0301-620X.99B1.BJJ-20160415.R1

33. Lazennec J-Y, Brusson A, Rousseau M-A (2011) Hip-spine relations and sagittal balance clinical consequences. Eur Spine J 20:1-13. https://doi.org/10.1007/s00586-011-1937-9

34. Rivière C, Lazic S, Dagneaux L et al (2018) Spine-hip relations in patients with hip osteoarthritis. EFORT Open Rev 3:39-44. https ://doi.org/10.1302/2058-5241.3.170020

Publisher's Note Springer Nature remains neutral with regard to jurisdictional claims in published maps and institutional affiliations. 